\title{
Reduced Doses of Docetaxel and Cisplatinum Plus 5 Fluorouracil Combination Chemotherapy in Metastatic Esophagogastric Adenocarcinoma: The Impact on Outcomes
}

\author{
Tulay EREN ${ }^{1}$, Nuriye OZDEMIR ${ }^{2}$, Ozan YAZICI ${ }^{3}$, Goksen I. IMAMOGLU ${ }^{1}$, Dogan YAZILITAS ${ }^{1}$, \\ Süheyla A. ARSLAN ${ }^{4}$, Nurullah ZENGIN ${ }^{2}$ \\ ' Diskapi Yıldırım Beyazıt Research and Training Hospital, Department of Oncology \\ ${ }^{2}$ Yıldırım Beyazit University, Faculty of Medicine, Department of Oncology \\ ${ }^{3}$ Numune Research and Training Hospital, Department of Oncology \\ ${ }^{4}$ Yıldırım Beyazıt University, Faculty of Medicine, Department of Radiation Oncology, Ankara, TURKEY
}

\begin{abstract}
Docetaxel-cisplatin-5-fluorourasil (DCF) protocol is one of the standard regimen at present however it is difficult to administer owing to high toxicity rates. The aim of study was to modify the dose of DCF regimen in order to render it more tolerable and to evaluate the efficacy and tolerability of modified DCF (mDCF) protocol. 267 patients followed in Ankara Numune Hospital were included in the study. All patients were administered mDCF regimen as metastatic first line treatment. Doses in mDCF arm was as follows: docetaxel $60 \mathrm{mg} /$ $\mathrm{m}^{2}$ 1. day, cisplatin $60 \mathrm{mg} / \mathrm{m}^{2}$ 1. day and 5-fluorouracil $600 \mathrm{mg} / \mathrm{m}^{2} /$ day (1-5 days) every three weeks In the study, files of overall 267 patients who did not previously receive treatment were evaluated retrospectively. Median number of cycles in all patients was 6 (range 2-10). Median age of patients was 55 (range 22-76). Median follow up period was 9 months. Complete response 5 (1.9\%) patients, partial response 74 (27.7\%) patients and stable disease 95 (35.6\%) patient. Median PFS was 6.0 (95\%Cl, 5.3-6.6) months, and median OS 10.0 (95\% Cl, 8.8-11.1) months. Parameters effect in univariate analysis were submitted to multivariate analysis results were CEA, grade, ECOG effective on OS. Grade 3-4 neutropenia was found 28.1\%, anemia 11.6\%, thrombocytopenia $4.1 \%$ and Febrile neutropenia $4.9 \%$. Although mDCF regimen seems to be as effective as original DCF regimen, grade 3-4 toxicity rates were found to be lower. mDCF may be preferred as a tolerable and effective regimen in ECOG 0-2 metastatic gastric cancers.

Keywords: Metastatic esofagogastric cancer, Modified DCF, mDCF, Efficacy, Toxicity, Progression free survival, Overall survival
\end{abstract}

ÖZET

Metastatik Özofagogastrik Adenokarsinomlarda Modifiye Doz Dosetaksel-Sisplatin-5-Fluorourasil Kombinasyon Tedavisi: Sonuçlara Etkisi

Günümüzde metastatik mide kanserinde Dosetaksel-cisplatin-5-fluourasil (DCF) standart tedavi rejimlerinden biridir ancak yüksek toksisite oranları nedeniyle uygulaması zordur. Çalışmamızın amacı DCF rejiminin modifiye dozlarda etkinlik ve tolerabilitesinin gösterilmesidir. Çalışmaya Ankara Numune Hastanesinde takipli 267 hasta alındı. Tüm hastalar metastatik birinci basamakta modifiye DCF (mDCF) rejimi aldı. mDCF de ilaç dozları dosetaksel $60 \mathrm{mg} / \mathrm{m}^{2}$ 1. gün, sisplatin $60 \mathrm{mg} / \mathrm{m}^{2}$ 1. gün ve 5 -fluourasil $600 \mathrm{mg} / \mathrm{m}^{2} / \mathrm{gün}$ (1-5 günler) üç hastada bir olarak verildi. Çalışmada daha önce tedavi almamış 267 hastanın dosyaları retrospektif olarak incelendi. Hastaların aldığı median kür sayısı 6 (2-10), median yaş 55 (22-76) idi. Median takip süresi 9 ay idi. Tam yanıt 5 (1.9\%) hastada, parsiyel yanıt 74 (\%27.7) hastada, stabil hastalık 95 (\%35.6) hastada tespit edildi. Median PFS 6.0 (\%95 Cl, 5.3-6.6) ay, median OS 10.0 (\%95 Cl, 8.8-11.1) ay olarak bulundu. Multivariate analizde OS üzerine etki eden faktörler CEA düzeyi, tümör greydi ve ECOG skoruydu. Grade 3-4 nötropeni \%28.1, anemi \%11.6, trombositopeni \%4.1 olarak bulundu. Febril nötropeni oranı \%4.9 idi. mDCF rejimi orijinal DCF rejimi kadar etkilidir, grade 3-4 toksisite oranları daha düşüktür. mDCF, ECOG 0-2 metastatik mide kanserinde etkili ve daha tolerabl bir rejim olarak tercih edilebilir.

Anahtar Kelimeler: Metastatik özefagogastrik kanser, Modifiye DCF, mDCF, Etkinlik, Toksisite, Hastalıksız sağ kalım, Genel sağ kalım 


\section{INTRODUCTION}

Gastric cancer is a health problem that occurs frequently all over the world and is of significance for public health. According to epidemiological data, in 2011, all over the world, gastric cancer is the fourth most common cancer, following lung, breast and colorectal cancers. Throughout the world 989.600 new cases are diagnosed annually and 738.000 cases die of gastric cancer, which accounts for $10 \%$ of all cancer related deaths. ${ }^{1}$ Metastatic gastric cancer has an unfavorable prognosis and mean survival is between 3-5 months unless it is treated. ${ }^{2,3,4}$ At present, expected survival is quite short despite all current advances and large majority of patients die within one year of metastasis development.

At present, there is no gold standard chemotherapy in the treatment of metastatic gastric cancer. According to results of randomized studies and meta-analyses, in metastatic gastric cancer cases, chemotherapy is more effective than supportive treatment with regard to both quality of life and survival. ${ }^{5,6} 5$-Flourouracil and platins are most frequently used drugs. Then, it was demonstrated that addition of taxane groups chemoteurpatic drugs to these (docetaxel or paclitaxel) may improve treatment outcomes. . $^{7,8,9,10}$

After the efficacy of Docetaxel was shown in gastric cancer monotherapy ${ }^{11-16}$, it started to be combined with other agents. ${ }^{17-20}$ Investigators have designed TAX 325 study in order to examine the addition of docetaxel to reference regimen in gastric cancer, i.e. cisplatin-5-FU (CF) combination. ${ }^{21,22}$ Although TAX 325 demonstrated that in patients with metastatic gastroesophageal cancer, the addition of docetaxel to $\mathrm{CF}$ combination increased disease free survival and overall survival rates, it also had high dose limiting toxicity. Standard dose DCF regimen started to be new reference regimen in metastatic gastroesophageal cancer. However, it was a regimen difficult to administer due to its high toxicity rates. These results led to retrospective and then prospective studies investigating the efficacy and reliability of same combination at modified doses. ${ }^{23}$

In the present study, doses of DCF regimen, whose efficacy was shown in metastatic gastric cancer but is toxic regimen, were modified. The aim of the present study was to evaluate long term real life data of efficacy and toxicity of $\mathrm{mDCF}$ regimen.

\section{PATIENTS AND METHODS}

Patients who were followed in Ankara Numune Research and Education Hospital Medical Oncology clinic with the diagnosis of metastatic gastric cancer between 2005-2015 were included in the study. 267 patients file who had metastasis at the time of diagnosis or at follow up and underwent treatment with $\mathrm{mDCF}$ combination as first line treatment were examined retrospectively. All patient data were investigated in terms of demographic characteristics such as age and sex, pathological characteristics, and reliability. Long term vital data of the patients was accessed via Turkish population administrative data in addition to their files.

In the evaluation of patient performance while receiving $\mathrm{mDCF}$, Eastern Cooperative Oncology Group (ECOG) scale and in the evaluation of response to treatment Response Evaluation Criteria in Solid Tumors (RECIST ver.1.1) criteria were used. The evaluation of treatment toxicity was made according to data of National Cancer Institute Common Toxicity Criteria (NCI-CTC ver. 2.0)

\section{Treatment}

All patients were administered docetaxel $60 \mathrm{mg} /$ $\mathrm{m}^{2} 1$. day, cisplatin $60 \mathrm{mg} / \mathrm{m}^{2} 1$. day, 5-fluorouracil $600 \mathrm{mg} / \mathrm{m}^{2} 1-5$ days every three weeks. Prior to treatment, all patients underwent whole blood, kidney function and liver function tests in order to determine whether they were suitable for treatment. All patients receiving $\mathrm{mDCF}$ treatment after 2011 were routinely administered Aprepitant as antiemetic.

\section{Statistics}

Data analysis was carried out by SPSS 18.0 for Windows program. Descriptive statistics was expressed with mean-standard deviation or median (lowest-highest values) for continuous numerical variables and number of cases and (\%) for categorical variables. 


\begin{tabular}{|c|c|c|}
\hline Variables & $\mathbf{n}$ & $\%$ \\
\hline Age of diagnosis (median) & 55 (22-76) & \\
\hline \multicolumn{3}{|l|}{ Sex } \\
\hline Male & 196 & 73.4 \\
\hline Female & 71 & 26.6 \\
\hline \multicolumn{3}{|l|}{ Tumor location } \\
\hline Cardia & 34 & 12.7 \\
\hline Fundus & 42 & 15.7 \\
\hline Corpus & 120 & 44.9 \\
\hline Pylor & 41 & 15.4 \\
\hline All gastric & 30 & 11.2 \\
\hline \multicolumn{3}{|l|}{ Weight loss at diagnosis } \\
\hline Weight loss present & 173 & 64.8 \\
\hline Weight loss absent & 94 & 35.2 \\
\hline \multicolumn{3}{|l|}{ Anemia at diagnosis } \\
\hline Anemia present & 221 & 82.8 \\
\hline Anemia absent & 46 & 17.2 \\
\hline \multicolumn{3}{|l|}{ Tumor Grade } \\
\hline I & 17 & 6.4 \\
\hline$\|$ & 65 & 24.3 \\
\hline III & 152 & 56.9 \\
\hline Unknown & 33 & 12.4 \\
\hline \multicolumn{3}{|l|}{ ECOG } \\
\hline 0 & 42 & 15.7 \\
\hline 1 & 174 & 65.2 \\
\hline 2 & 51 & 19.1 \\
\hline \multicolumn{3}{|l|}{ Metastasis locations } \\
\hline Visceral & 212 & 79.4 \\
\hline Non-Visceral & 55 & 20.6 \\
\hline \multicolumn{3}{|l|}{ Adjuvant treatment } \\
\hline Adjuvant chemotherapy & 43 & 16.1 \\
\hline Adjuvant chemoradiotherapy & 39 & 14.6 \\
\hline
\end{tabular}

Progression and overall survival rates of all cases were investigated using Kaplan-Meier survival analysis. 3 months, 6 months, 9 months, 1 year, 2 years and 3 years cumulative progression free and overall survival rates along with mean survival were calculated with their $95 \%$ confidence intervals. Demographic characteristics of patients were evaluated using descriptive statistical methods. Parameters which were significant in univariate analysis were submitted to Cox regression multivariate analysis.

\section{RESULTS}

\section{Demographic Characteristics}

267 patients were included in the present study. Median age was 55 (range 22-76). One hundered

\begin{tabular}{|lcc|}
\hline $\begin{array}{l}\text { Table 2. Survival rates in patients undergoing mDCFchemo- } \\
\text { therapy. }\end{array}$ & $\begin{array}{l}\text { Progression free } \\
\text { survival }\end{array}$ & Overall survival \\
\hline Survival rates & $55 \%$ & $76 \%$ \\
\hline 6 months & $18 \%$ & $41 \%$ \\
1 Year & $5 \%$ & $14 \%$ \\
2 Years & 5 & \\
\hline
\end{tabular}

ninethy-six of cases was $(73,4 \%)$ male and $71(26$, $6 \%$ ) female. At the moment of diagnosis, there was weight loss in $64.8 \%$ of patients and anemia in $82.8 \%$ of patients. Primary tumor localization was gastric corpus in nearly half of patients (44.9\%), cardia tumor was observed only in $12.7 \%$ of patients. About $80 \%$ of patients were metastatic at the moment of diagnosis and over 50\% was histopathologic grade 3 .

In Table 1, demographic characteristics of patients are demonstrated.

\section{Treatment Characteristics and Efficacy Data}

In all patients, median number of $\mathrm{mDCF}$ cycles was 6 (range 2-10). When best response rates obtained with $\mathrm{mDCF}$ regimen were evaluated, it was observed that complete response was found in 5 $(1,9 \%)$ patients, partial response in $74(27.7 \%)$ patients, and stable disease in $95(35.6 \%)$ patients. Control rate of disease was found to be $65.2 \%$. In $34.8 \%$ of patients progression developed under treatment. During follow up, progression was observed in $92.5 \%$ while $7.5 \%$ was being followed without progression. Survival rates are shown in Table 2.

Median follow up period was 9 months. Median progression free survival was 6.0 (95\% CI, 5.3-6.6) months, while median overall survival was 10.0 (95\% CI, 8.8-11.1) months. Overall survival and disease-free survival curves of patients included in the study are depicted in Figure 1 and Figure 2.

In the univariate analysis of factors that can influence survival, weight loss prior to $\mathrm{mDCF}$, ECOG performance of 2, high tumor grade, presence of lymphovascular invasion and high CEA levels were established to exert inverse effect on overall 


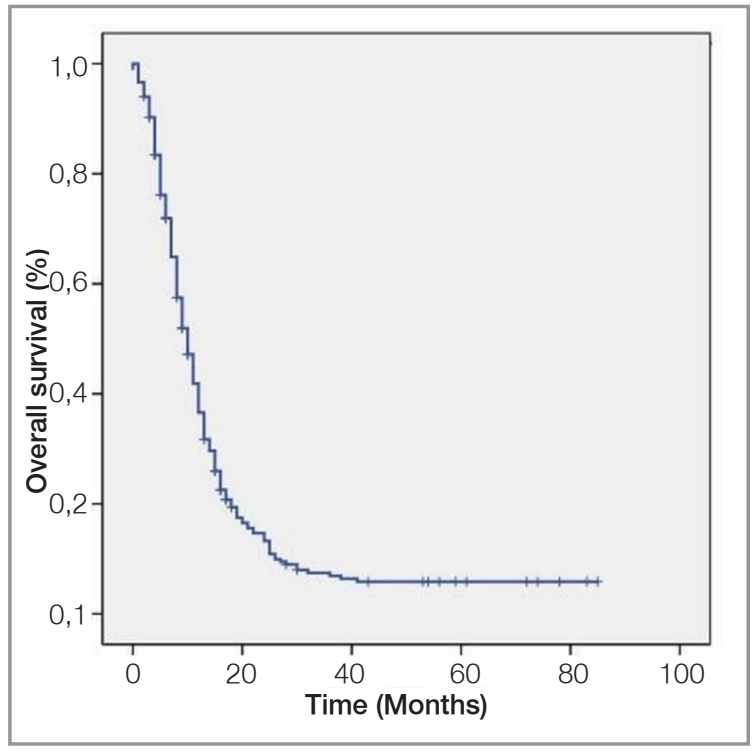

Figure 1. Overall survival graphic

survival. When parameters with significant effect in univariate analysis were submitted to multivariate analysis the results were as follows: CEA, grade, ECOG performance status still remained significantly effective on OS.

In Table $3 \mathrm{a}$ and $3 \mathrm{~b}$, univariate and multivariate analysis results are shown.

\section{Toxicity Data}

The most commonly occurring grade 3-4 side effects after $\mathrm{mDCF}$ chemotherapy were hematological. Grade 3 and 4 neutropenia rates were respectively $15 \%$ and $13 \%$. Neutropenic fever was observed in $4.9 \%$ of patients after $\mathrm{mDCF}$ chemotherapy and inpatient treatment was required in all of these patients.

Due to toxicity development cure was delayed in $15.4 \%$ of patients. The most frequent cause of cure delays was neutropenia at a rate of $9.4 \%$. Due to toxicity in $14.6 \%$ of patients dose modification was required. The most common cause of modification was again neutropenia at $10.9 \%$ during treatment, toxic death occurred in two patients.

When patients were evaluated for non-hematological toxicities, grade 3 nausea was seen in five patients $(1.9 \%)$ grade 3 vomiting in three patients, (1.1\%) grade 3-4 diarrhea in five patients (1.9\%),

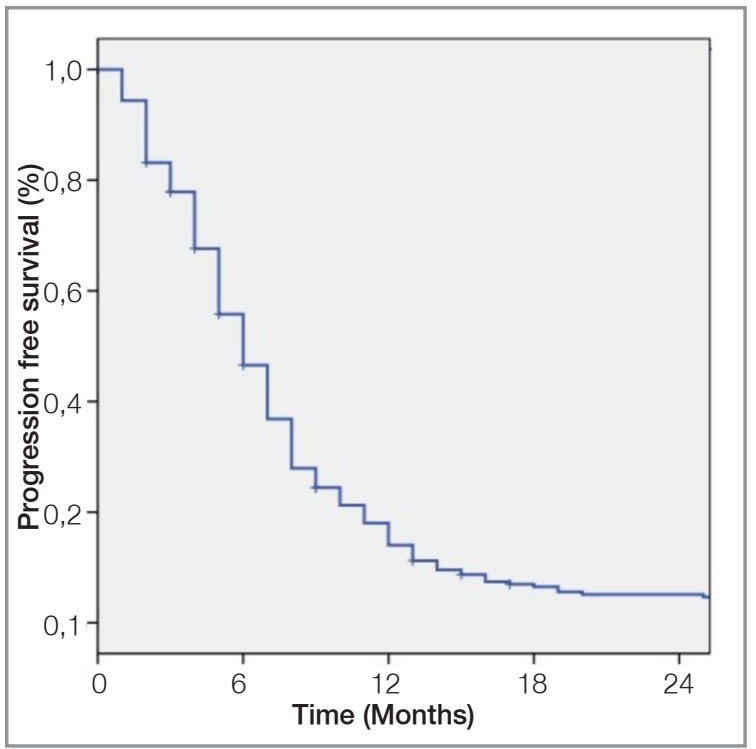

Figure 2. Progression free survival graphic

grade 3-4 nephrotoxicity in two patients $(0.8 \%)$ and grade 3 hepatotoxicity in three patients $(1.1 \%)$.

Hematological and non-hematological toxicity rates are demonstrated in Table 4.

\section{DISCUSSION}

Today, the treatment of metastatic gastric cancer is systemic chemotherapy. In Phase 3 randomized TOGA study, in which clinical efficacy of trastuzumab an antiHER-2 agent, was investigated, particularly in HER-2 positive patients, trastuzumab combination prolonged survival significantly. ${ }^{24}$ The overall survival benefit of these agents in bevacizumab and cetuximab studies has not been demonstrated. ${ }^{25,26}$ In our daily practice, standard approach in first line treatment of patients with metastatic gastric cancer whose HER-2 status in unknown or negative is systemic combination treatment. Nevertheless, there is no chemotherapy combination regimen that can be considered as gold standard. After the publication of TAX 325 study results, $\mathrm{mDCF}$ combination regimen has become one of the first line treatment regimen in our clinic. Our data have been collected retrospectively, but high number of patients and their being real life data may make our study worthwhile. 


\begin{tabular}{|c|c|c|c|}
\hline & \multicolumn{3}{|c|}{ Univariate analysis } \\
\hline & os & Cl (\%95) & $p$ value \\
\hline Weight loss & & & 0.031 \\
\hline Present & 9 & $7.8-10.1$ & \\
\hline Absent & 11 & $9.1-12.8$ & \\
\hline Tumor Grade & & & 0.01 \\
\hline High Grade & 9 & $7.9-10$ & \\
\hline Low Grade & 12 & $9.9-14$ & \\
\hline Lymphovascular invasion & & & 0.022 \\
\hline Present & 12 & $10.4-13.5$ & \\
\hline Absent & 14 & $7.6-20.3$ & \\
\hline CEA value & & & 0.014 \\
\hline High & 8 & $6.4-9.5$ & \\
\hline Normal & 12 & $10.5-13.4$ & \\
\hline ECOG value & & & 0.02 \\
\hline ECOG 2 & 7 & $5.2-8.7$ & \\
\hline ECOG 0-1 & 11 & $9.7-12.2$ & \\
\hline
\end{tabular}

Study of Van Cutsem et al. (TAX 325 study), on which our practice is based, DCF regimen was administered as docetaxel $75 \mathrm{mg} / \mathrm{m}^{2} 1$. day, cisplatin $75 \mathrm{mg} / \mathrm{m}^{2} 1$. day and $5-\mathrm{FU} 750 \mathrm{mg} / \mathrm{m}^{2} /$ day $(1-5$. days) every three weeks and in $\mathrm{mDCF}$ regimen, doses were administered in the same manner after being modified at $20 \%$. In the recently published phase 3 randomized studies of Jinwan Wang et al, $\mathrm{mDCF}$ regimen, with similar dose and administration pattern with our study, was compared with $\mathrm{CF}$ regimen and $\mathrm{mDCF}$ regimen was established to yield significantly higher PFS and OS compared to CF regimen. ${ }^{27}$

Control rate of disease was found to be $67 \%$ in TAX 325 study and $65.2 \%$ in the our study. In

\begin{tabular}{|c|c|c|}
\hline & $\mathbf{n}$ & $\%$ \\
\hline Dose reduction due to toxicity & 39 & 14.6 \\
\hline Treatment discontinuation due to toxicity & 41 & 15.4 \\
\hline Death due to treatment & 2 & 0.7 \\
\hline \multicolumn{3}{|l|}{ Grade 3-4 toxicity } \\
\hline Neutropenia & 75 & 28.1 \\
\hline Anemia & 31 & 11.6 \\
\hline Thrombocytopenia & 11 & 4.1 \\
\hline Nausea & 5 & 1.9 \\
\hline Vomiting & 3 & 1.1 \\
\hline
\end{tabular}

\begin{tabular}{|c|c|c|c|}
\hline & \multicolumn{3}{|c|}{ Multivariate analysis } \\
\hline & HR & Cl (\%95) & $p$ value \\
\hline Tumor Grade & & & 0.005 \\
\hline High Grade & 1 & & \\
\hline Low Grade & 0.46 & $0.26-0.79$ & \\
\hline CEA value & & & 0.03 \\
\hline High & 1 & & \\
\hline Normal & 0.60 & $0.37-0.95$ & \\
\hline ECOG value & & & 0.001 \\
\hline ECOG 2 & 1 & & \\
\hline ECOG 0-1 & 0.35 & $0.19-0.64$ & \\
\hline
\end{tabular}

terms of disease control rates, $\mathrm{mDCF}$ seems to reach the efficacy level of original doses. In TAX 325 study, mean time to progression was found to be 5.6 months and mean overall survival 9.2 months. In the study of Jinwan Wang using mDCF regimen, PFS of 7.2 months and OS 10.2 months were obtained while in the our study, PFS obtained was 6.0 months and OS 10.0 months, which are similar to results of above studies. Furthermore, all patients had ECOG status 0-1 in other phase studies, whilst $20 \%$ of our study groups consisted of ECOG 2 patients.

In a small randomized study comparing $\mathrm{mDCF}$ and standard DCF, modified regimen obtained 18 months OS whereas standard dose yielded 12 months OS. These figures are longer than all previous DCF data. The difference may be attributed to high number of locally advanced patients and to some patients undergoing surgery after tumor size is decreased. In addition, some of these patients underwent surgery after neoadjuvant treatment. ${ }^{28}$

In the study of Inal et al, 107 patients were evaluated retrospectively to compare $\mathrm{mDCF}$ and standard DCF regimen and in $\mathrm{mDCF}$ arms, modified doses similar to those of our study were administered and OS values were found to be 9.9 months in DCF arm and 8.6 months in mDCF arm. PFS was found to be 7.4 months in DCF arm and 6.5 months in mDCF arm. ${ }^{29}$

TAX 325 study indicated that DCF regimen is one difficult to administer although it is an effective combination. In Standard DCF, grade 3-4 neutro- 
penia was observed at the rate of $82 \%$, neutropenic fever $29 \%$, and diarrhea $19 \%$. In the study of Jinwan Wang, in mDCF arm, grade 3-4 neutropenia was found at the rate of $60 \%$ and febrile-neutropenia $12 \%$. In our study, grade 3-4 neutropenia was found at the rate of $28 \%$, and febrile-neutropenia around $5 \%$. In the our study, the lower rate of hematological toxicity may be due to the fact that our data was collected retrospectively.

In TAX 325 study, in $64 \%$ of patients treatment was delayed and in $41 \%$ doses was reduced. Toxic death rate was found to be $2.7 \%$. In our study, treatment delaying occurred at the rate of $15 \%$ and dose reduction $14 \%$. Toxic death was occurred only in two patients. As seen, there is significant difference between standard dose and modified dose in terms of both delay in treatment and dose reduction. These delays and dose reductions in standard DCF may be the most important factor limiting its efficacy.

In the study of Inal et al. grade 3-4 neutropenia was found at the rate of $48.2 \%$ in standard DCF arm and $13.6 \%$ in mDCF arm. In this study, overall survival and progression free survival rates similar to those of our study were obtained and toxicity results were found to be quite lower than original doses. ${ }^{29}$

In conclusion, metastatic gastric cancer has no prospect of survival and main aim of treatment should be palliation or prolongation of survival. However, in a patient group in which cure is not expected, we should take care not to impair quality of life further and not to prolong the duration of hospitalization while trying to improve OS data. In this respect, $\mathrm{mDCF}$ is as effective as standard DCF. Furthermore, its tolerability is much better. In the present study, it was demonstrated that modified DCF regimen is an effective and reliable regimen as real-life data.

\section{REFERENCES}

1. Jemal A, Bray F, Center MM, et al. Global cancer statistics. CA Cancer J Clin 61: 69-90, 2011.

2. Murad AM, Santiago FF, Petroianu A, at al. Modified therapy with 5-fluorouracil, doxorubicin, and methotrexate in advanced gastric cancer. Cancer 72: 37-41, 1993.
3. Glimelius B, Ekström K, Hoffman K, et al. Randomized comparison between chemotherapy plus best supportive care with best supportive care in advanced gastric cancer. Ann Oncol 8: 163-168, 1997.

4. Pyrhönen S, Kuitunen T, Nyandoto $P$, at al. Randomised comparison of fluorouracil, epidoxorubicin and methotrexate (FEMTX) plus supportive care with supportive care alone in patients with non-resectable gastric cancer. $\mathrm{Br} \mathrm{J}$ Cancer 71: 587-591, 1995.

5. Wagner AD, Grothe W, Haerting J, at al. Chemotherapy in advanced gastric cancer: a systematic review and metaanalysis based on aggregate data. J Clin Oncol 24: 29032909, 2003.

6. Casaretto L, Sousa PL, Mari JJ. Chemotherapy versus support cancer treatment in advanced gastric cancer: a meta-analysis. Braz J Med Biol Res 39: 431-440, 2006.

7. Eric Van Cutsem. The treatment of advanced gastric cancer: new findings on the activity of the taxanes. The Oncologist 9: 9-15, 2004.

8. Vanhoefer U, Wilke H, Harstrick A. Phase II study of docetaksel as second line chemotherapy in metastatic gastric cancer. Proc Am Soc Clin Oncol 18: 1163, 1999.

9. Taguchi T, Sakata Y, Kanamaru R, at al. Phase II clinical study of RP56976 (docetaxel) in patients with advanced/ recurrent gastric cancer: a Japanese Cooperative Study Group trial (group A). Gan To Kagaku Ryoho 25: 19151924, 1998.

10. Di Cosimo S, Ferretti G, Fazio N, at al. Docetaxel in advanced gastric cancer-review of the main clinical trials. Acta Oncol 42: 693-700, 2003.

11. Bang YJ, Kang WK, Kang YK, at al. Docetaxel 75 mg/m2 is active and well tolerated in patients with metastatic or recurrent gastric cancer: a phase II trial.Jpn J Clin Oncol 32: 248-254, 2002.

12. Einzig Al, Neuberg D, Remick SC, at al. Phase II trial of docetaxel (Taxotere) in patients with adenocarcinoma of the upper gastrointestinal tractpreviously untreated with cytotoxic chemotherapy:the Eastern Cooperative Oncology Group (ECOG) results of protocol E1293. Med Oncol 13: 87-93, 1996.

13. Graziano F, Catalano V, Baldelli AM, at al. A phase II study of weekly docetaxel as salvage chemotherapy for advanced gastric cancer. Ann Oncol 11: 1263-1266, 2000.

14. Mai M, Sakata Y, Kanamaru R, at al. A late phase II clinical study of RP56976 (dosetaksel) in patients with advanced or recurrent gastric cancer: A Cooperative Study Group trial (group B). Jpn J Cancer Chemother 26: 487-496, 1999.

15. Mavroudis D, Kourousis C, Androulakis N, at al. Frontline treatment of advanced gastric cancer with docetaxel and granulocyte colony-stimulating factor (G-CSF): a phase II trial. Am J Clin Oncol 23: 341-344, 2000. 
16. Sulkes A, Smyth J, Sessa C, at al.Docetaxel (Taxotere) in advanced gastric cancer: results of a phase II clinical trial. EORTC Early Clinical Trials Group.Br J Cancer 70: 380373, 1994.

17. Roth AD, Maibach R, Martinelli G, at al. Docetaxel (Taxotere)-cisplatin (TC): an effective drug combination in gastric carcinoma. Swiss Group for Clinical Cancer Research (SAKK), and the European Institute of Oncology (EIO). Ann Oncol 11: 301-306, 2000.

18. Hawkins R, Cunningham D, Soerbye H. Randomized phase II trial of docetaksel plus irinotekan vsdocetaksel plus 5-fluorouracil in patients with untreated advanced gastric adenocarcinoma. Proc Am Soc Clin Oncol 22: 257, 2003.

19. Ridwelski K, Gebauer T, Fahlke J, at al. Combination chemotherapy with docetaxel and cisplatin for locally advanced and metastatic gastric cancer. Ann Oncol 12: 47 51, 2001.

20. Constenla M, Garcia-Arroyo R, Lorenzo I, at al. Docetaxel, 5-fluorouracil, and leucovorin as treatment for advanced gastric cancer: results of a phase II study. Gastric Cancer 5: 142-147, 2002.

21. Van Cutsem E, Moiseyenko VM, Tjulandin S, at al. Phase III study of docetaxel and cisplatin plus fluorouracil compared with cisplatin and fluorouracil as first-line therapy for advanced gastric cancer: a report of the V325 Study Group. J Clin Oncol 24: 4991-4997, 2006.

22. Nishiyama M, Wada S. Docetaxel: its role in current and future treatments for advanced gastric cancer. Gastric Cancer 12: 132-141, 2009.

23. Ajani JA. Optimizing docetaxel chemotherapy in patients with cancer of the gastric and gastroesophageal junction: evolution of the docetaxel, cisplatin, and 5-fluorouracil regimen. Cancer 113: 945-955, 2008.

24. Bang YJ, Van Cutsem E, Feyereislova A, at al. ToGA Trial Investigators Trastuzumab in combination with chemotherapy versus chemothrapy alone for treathment of HER2 positive advenced gastric or gasro-oesophagealjuction cancer (ToGA) a phase 3 open label randomisedcontroled trial. Lancet 376: 687-697, 2010.
25. Ohtsu A, Shah MA, Van Cutsem E, at al.Bevacizumab in combination with chemotherapy as first-line therapy in advanced gastric cancer: arandomized, double-blind, placebo-controlled phase III study. J Clin Onco I29: 39683976, 2011.

26. Lordick F, Kang YK, Chung HC, at al. Capecitabine and cisplatin with or without cetuximab for patients with previously untreated advanced gastric cancer (EXPAND): a randomised, open-label phase 3 trial. Lancet Oncol 14: 490-499, 2013.

27. Wang J, Xu R, Li J, at al. Randomized multicenter phase III study of a modified docetaxel and cisplatin plus fluorouracil regimencompared with cisplatin and fluorouracil as firstline therapy for advanced or locally recurrent gastric cancer. Gastric Cancer 19: 234-244, 2016.

28. Shah MA, Janjigian $Y Y$, Stoller $R$, at al.Randomized Multicenter Phase II Study of Modified Docetaxel, Cisplatin, and Fluorouracil (DCF) Versus DCF Plus Growth Factor Support in Patients With Metastatic Gastric Adenocarcinoma: A Study of the US Gastric Cancer Consortium. J Clin Oncol 33: 3874-3879, 2015.

29. Inal A, Kaplan MA, Kucukoner M, at al. Docetaxel and Cisplatin Plus Fluorouracil compared with Modified Docetaxel, Cisplatin, and 5-Fluorouracil as first-line therapy for advanced gastric cancer: a retrospective analysis of single institution. Neoplasma 59: 233-236, 2012.

\section{Correspondence:}

Dr. Tülay EREN

Diskapi Yildirim Beyazit Arastirma ve Egitim Hastanesi

Onkoloji Bölümü

Diskapi, ANKARA / TURKEY

Tel: (+90-312)-596 3089

Fax: (+90-312)-318 6690

e-mail: tulayeren78@gmail.com 